\title{
Antioxidant Activity Level, Bioactive Compounds, Colour and Spectroscopic Analysis (UV-Vis and FT-IR) of Flavoured Drinks Made with Wine and Sour Cherries (Prunus cerasus Var. austera)
}

\author{
Michela Pisani ${ }^{1}\left(\mathbb{D}\right.$, Paola Astolfi $^{1}$ (D), Simona Sabbatini ${ }^{1}$ and Patricia Carloni ${ }^{2, *}$ \\ 1 Department of Science and Engineering of Materials, Environment and Urban Planning-SIMAU, \\ Marche Polythecnic University, Via Brecce Bianche 12, I-60131 Ancona, Italy; m.pisani@univpm.it (M.P.); \\ p.astolfi@univpm.it (P.A.); s.sabbatini@univpm.it (S.S.) \\ 2 Department of Agricultural, Food and Environmental Sciences-D3A, Marche Polythecnic University, \\ Via Brecce Bianche, I-60131 Ancona, Italy \\ * Correspondence: p.carloni@univpm.it
}

\section{check for} updates

Citation: Pisani, M.; Astolfi, P.; Sabbatini, S.; Carloni, P. Antioxidant Activity Level, Bioactive Compounds, Colour and Spectroscopic Analysis (UV-Vis and FT-IR) of Flavoured Drinks Made with Wine and Sour Cherries (Prunus cerasus Var. austera). Foods 2021, 10, 1953. https:/ /doi.org/ 10.3390 /foods10081953

Academic Editor: Severino Matias De Alencara

Received: 16 July 2021

Accepted: 20 August 2021

Published: 22 August 2021

Publisher's Note: MDPI stays neutral with regard to jurisdictional claims in published maps and institutional affiliations.

Copyright: (c) 2021 by the authors. Licensee MDPI, Basel, Switzerland. This article is an open access article distributed under the terms and conditions of the Creative Commons Attribution (CC BY) license (https:// creativecommons.org/licenses/by/ $4.0 /)$.

\begin{abstract}
In recent years, the increase in consumer interest towards simpler and authentic lifestyles has led to an explosive growth in the production and business of typical agri-food products and, among these, of wines and its derived beverages. With the aim of promoting a typical Italian beverage, the so-called "Vino di visciole" or "Visner", listed in the national table of traditional agrifood products, the antioxidant and colour properties of fifteen samples from different provinces of the Marche region and obtained with different recipes were analysed. The "in vitro" total antioxidant activity (TAA) determined using ABTS assays, total phenolic content (TPC), total flavonoid content (TFC), total anthocyanins content (TAC), and colour (Somers assay) were measured. In addition, a spectroscopic FT-IR and UV-Vis analysis was carried out to analyse samples with multivariate techniques. The results showed that the production area, the recipe, and the type of cherries used to make the alcoholic beverage do not influence the antioxidant properties and the phytochemical contents of the samples. The multivariate treatment of the spectroscopic features (mainly UV-Vis) rather allowed the differentiation of samples with high antioxidant activity using easy and low-cost instrumental techniques that require little time and can be employed in routine analysis.
\end{abstract}

Keywords: traditional product; ABTS; phenolics; flavonoids; visner; visciole; PCA

\section{Introduction}

One of the predominant trends in agro-industrial markets reveals a growing interest among consumers in traditional products closely linked to a specific place of origin. In fact, customers show a greater propensity to purchase food or agro-industrial products deeply rooted in various popular cultures and perceived as authentic and genuine, even if this means paying higher prices. The growth in international trade, the proliferation of multinational companies with standardised products, and the gradual homogenisation of supplies resulted in an increase in the number of consumers willing to pay a premium to consume regional products that retain the quality of the past and have not been "tainted" by what many people regard as rampant modernisation [1]. Consumers also associate the quality of food with handling along the food production chain and to the correlated chemical risk due to the addition of substances including pesticides, antibiotics, preservatives, and food colouring [2,3].

Nowadays, regional products are not limited to the restricted areas in which they are produced but can reach local, national, or international markets and their "denomination" as regional or typical products is linked to the particularities of their geographic milieu, 
their quality, and their fame. This identification is a tool for the national and international recognition of the heritage and food culture of the various regions and countries.

Attention to the regionality of foods is often strictly linked to an increased interest in their beneficial effects on human health and on diseases prevention. This results in an enlarged consumer demand for functional foods and, in particular, vegetables and fruits with their phytochemicals that are able to prevent diseases caused by oxidative stress [4]. Phytochemical action has been attributed to their high free radical scavenging capacity that could contribute to, or enhance by induction, the endogenous antioxidant properties of living cells or organisms.

Concerning the antioxidant properties of fruits, a key role is played by grapes and wine as well by berries, cherries, and their juices. In this context, an interesting regional product with high antioxidant potential is represented by a flavoured drink made with wine and sour cherries (Prunus cerasus var. austera) know by consumers as "Vino di visciole" or "Visner", and produced in the Marche region (Italy): it is a typical Italian alcoholic flavoured beverage ranging about $14 \%$ vol. Although the recipe followed to produce this beverage can have different variants and can make use of secret natural aromatic additives [5], traditionally, two main production techniques, differing for times and ways of fermentation, can be distinguished and are used in the different zones.

In red grape wine, many phytochemicals are present, providing antioxidant protection with a decrease in platelet aggregation and an increase in endothelial function. Wine polyphenols also prevent and attenuate inflammatory responses through a variety of mechanisms, thereby serving as possible cardioprotective, neuroprotective, and chemopreventive agents [6]. In sour cherries (Prunus cerasus L.), phenolic compounds are also present, which have a broad spectrum of beneficial effects for health: for example, they contain significant levels of anthocyanins with strong antioxidant and anti-inflammatory activities [7-10] and have protective effects on neuronal cells [11]. Moreover, in the past decade, sour cherry products' utilisation in the food market has increased because of their potential health benefits [12].

Therefore, given the growing consumer interest in traditional products and in their beneficial and genuine aspects, the "in vitro" antioxidant activity and bioactive compounds of different sour cherry beverages, other fruit spirits made with berries from different species of Prunus (cherries, black cherries, and blackthorn), and some local red wines were evaluated. To this regard, total antioxidant activity (TAA) using the ABTS assay, total phenolic content (TPC), total flavonoid content (TFC), total anthocyanins content (TAC), and colour were measured [13]. Moreover, in recent years, the use of spectroscopic techniques, such as UV, visible (Vis), near infrared (NIR), and mid-infrared (MIR) integrated with multivariate data analysis, has developed considerably in the de-termination of wine composition (including phenolic compounds). Given their speed and ease of use [14,15], the study of the wine samples was integrated with these analyses and statistically treated with the aim of understanding a possible relationship between composition, production area, and antioxidant properties [16].

\section{Materials and Methods}

\subsection{Chemicals and Equipment}

All reagents, including solvents of the highest purity available, were purchased from Sigma-Aldrich Chemical Co. (Milan, Italy) and used as received. Ultrapure water was used throughout and obtained from a Milli-Q system from Millipore (Milford, MA, USA).

Spectrophotometric measurements were recorded on a Varian Cary 50 UV-Visible spectrophotometer (Agilent Technologies Italia S.p.A., Milano, Italy) or on a microplate reader (Synergy HT, Biotek, Winooski, VT, USA).

\subsection{Samples}

The samples included fifteen (SCW01-15) beverages from wine and sour cherries (Prunus cerasus var. austera), one (BW) from wine and blackthorn (Prunus spinosa L.), one 
liquor (BCL) made with black cherries (Prunus cerasus var. amarena) and another liquor (CL) made with cherries (Prunus avium); in addition, for comparison, three (W01-03) local red wine were analysed. All samples were purchased from local retail shops. Sour cherry samples were classified according to the area of production declared on the commercial label and are described in detail in Supplementary Materials Table S1, together with all other samples. The production area is important because it is linked to the recipes used in the preparation of the beverage. Usually, in the Ancona province, cherries are initially sun-dried and then macerated with the addition of sugar for the whole summer period (about four months) resulting in a cherry syrup. After harvesting red grape at the end of summer, the must is added to the obtained cherries juice, and the mixture is left to ferment for 2-3 months. After fermentation, the product is filtered, bottled, and seasoned for $2-3$ months, typically without the addition of sulphites. Another recipe is commonly adopted in the Pesaro and Urbino province: sugar and red wine (not the red grape must) are added to the fresh cherries in summer, and the resulting mixture is left to ferment for two months; later, alcohol is added and the blend is left to stand for another 5-6 months before bottling. This technique is the most common and used to produce the typical "Visner" [17].

All sample were sub-sampled from freshly opened bottles and stored at $-20{ }^{\circ} \mathrm{C}$ until analysed.

\section{3. "In Vitro" Total Antioxidant Activity (TAA) Using ABTS Assay}

For measuring the "in vitro" antioxidant activity of the different samples, the ABTS assay was performed according to the method of Pellegrini et al. [18]. The radical cation $\left(\mathrm{ABTS}^{+} \bullet\right.$ ) was prepared by mixing a $7.0 \mathrm{mM}$ aqueous ABTS $\left(2,2^{\prime}\right.$-azinobis(3-ethylbenzothiazoline-6-sulfonic acid) diammonium salt) solution with a $2.45 \mathrm{mM}$ aqueous solution of potassium persulfate as oxidising agent in 0.9:0.1 ratio, and allowing the mixture to stand in the dark at room temperature for $12-16 \mathrm{~h}$. Prior to use, the ABTS ${ }^{+\bullet}$ stock solution was diluted $\sim 80: 1$ with water to obtain an absorbance at $734 \mathrm{~nm}$ ranging between 0.6-0.8. To $1.450 \mathrm{~mL}$ of this $\mathrm{ABTS}^{+\bullet}$ solution, $50 \mu \mathrm{L}$ of sample previously diluted 100:1 or Trolox (6-hydroxy-2,5,7,8-tetramethylchroman-2-carboxylic acid) standard ethanolic solution appropriately diluted with water, or water as control, were added and mixed. The obtained solution was left for $2 \mathrm{~h}$ in the dark at room temperature, and absorbance was read at $734 \mathrm{~nm}$ against water. Inhibition percentage values were calculated according to the Equation (1):

$$
\text { Inhibition of } A_{734}(\%)=\left(1-A_{c} / A_{0}\right) \times 100
$$

where $A_{c}=$ absorbance of the samples, $A_{0}=$ absorbance of the control.

Antioxidant activity was expressed as $\mathrm{mM}$ Trolox Equivalents (TE) using the linear regression value obtained from the Trolox calibration curve.

\subsection{Total Phenol Content (TPC)}

Total phenol content was determined using the Folin-Ciocalteu reagent [19]. To $1.00 \mathrm{~mL}$ water, $75 \mu \mathrm{L}$ of Folin-Ciocalteu reagent followed by $50 \mu \mathrm{L}$ of sample previously diluted 10:1, or gallic acid standard ethanolic solution appropriately diluted in water, or water as a blank, were added and mixed. After $10 \mathrm{~min}, 375 \mu \mathrm{L}$ of $20 \% \mathrm{Na}_{2} \mathrm{CO}_{3}$ were added, and the solution was left for $2 \mathrm{~h}$ at room temperature in the dark. Absorbance was read at $760 \mathrm{~nm}$, and the results were expressed as mM Gallic Acid Equivalents (GAE) using the linear regression value obtained from the gallic acid calibration curve.

\subsection{Total Flavonoid Content (TFC)}

The total flavonoid content in the samples was measured using a colorimetric assay according to the method of Gursoy et al. [20] with some modifications. Briefly, $50 \mu \mathrm{L}$ of sample previously diluted 10:1 with water, or (+)-catechin standard ethanolic solution appropriately diluted in water, or water as a blank, were added to $1.350 \mathrm{~mL}$ of distilled water. After mixing, $50 \mu \mathrm{L}$ of $5 \% \mathrm{NaNO}_{2}$ followed by $50 \mu \mathrm{L}$ of fresh prepared $10 \% \mathrm{AlCl}_{3}$ 
solution in water were added, and the resulting solution was left for $10 \mathrm{~min}$ at room temperature in the dark. Absorbance was read at $415 \mathrm{~nm}$, and the results were expressed as $\mathrm{mM}$ catechin equivalents (CE) using the linear regression value obtained from the catechin calibration curve.

\subsection{Total Anthocyanin Content (TAC)}

The total monomeric anthocyanin content in the samples was measured by the $\mathrm{pH}$ differential method described by Giusti and Wrolstad [21]. Briefly, $100 \mu \mathrm{L}$ of sample previously diluted 10:1 with water, or water as a blank, were added to $900 \mu \mathrm{L}$ of $0.025 \mathrm{M}$ potassium chloride buffer, $\mathrm{pH} 1.0$, or $0.4 \mathrm{M}$ sodium acetate buffer, $\mathrm{pH}$ 4.5. Absorbances of the two solutions at the different $\mathrm{pH}$ were read at 520 and $700 \mathrm{~nm}$. The net absorbance of each sample was calculated as $\mathrm{A}=\left(\mathrm{A}_{520}-\mathrm{A}_{700}\right) \mathrm{pH} 1.0-\left(\mathrm{A}_{520}-\mathrm{A}_{700}\right) \mathrm{pH}$ 4.5. The monomeric anthocyanin pigment concentration in the original sample was then calculated as $\mathrm{mg} / \mathrm{L}$ cyanidine 3-glucoside using the following formula (2):

$$
\text { Monomeric anthocyanin pigment }(\mathrm{mg} / \mathrm{L})=(\mathrm{A} \times \mathrm{MW} \times \mathrm{DF} \times 1000) /(\varepsilon \times 1)
$$

where MW is the cyanidine 3-glucoside molecular weight $\left(449.2 \mathrm{~g} \mathrm{~mol}^{-1}\right)$, DF is the dilution factor, and $\varepsilon$ is the molar absorptivity of cyanidine 3 -glucoside $\left(26,900 \mathrm{~L} \mathrm{~cm}^{-1} \mathrm{~mol}^{-1}\right)$.

\subsection{UV-Vis Measurements and Colour Parameters}

UV-Vis measurements were performed following the modified Somers assay [22], a set of spectroscopic measurements which can give a measure of wine colour, anthocyanin equilibria, and phenolic composition.

A buffer solution (TB) was prepared dissolving $1.5 \mathrm{~g}$ of tartaric acid $(0.5 \% \mathrm{w} / \mathrm{v})$ in $100 \mathrm{~mL}$ of $12 \%$ v/v ethanol solution adjusted to $\mathrm{pH} 3.4$ with $5 \mathrm{M} \mathrm{NaOH}$.

- Treatment "buffer": $270 \mu \mathrm{L}$ of the previously prepared TB solution was added to $30 \mu \mathrm{L}$ of sample and the absorbances at 420 and $520 \mathrm{~nm}$ were recorded.

- Treatment "sulphite": $270 \mu \mathrm{L}$ of a $0.375 \% w / v$ sodium metabisulfite solution in TB was added to $30 \mu \mathrm{L}$ of sample and the absorbance at $520 \mathrm{~nm}$ was recorded.

- Treatment "acetal": $270 \mu \mathrm{L}$ of a $0.1 \% v / v$ acetaldehyde solution in TB was added to $30 \mu \mathrm{L}$ of sample and after $60 \mathrm{~min}$ at room temperature in the dark the absorbances at 420 and $520 \mathrm{~nm}$ were recorded.

- Treatment " $\mathrm{HCl}^{\prime}: 1470 \mu \mathrm{L}$ of $1 \mathrm{M} \mathrm{HCl}$ solution was added to $30 \mu \mathrm{L}$ of sample and, after $3 \mathrm{~h}$ at room temperature in the dark, the absorbances from 250 to $700 \mathrm{~nm}$ were recorded at $\Delta \lambda=1 \mathrm{~nm}$ constant intervals.

- Colour parameters were calculated as described by Mercurio et al. [22].

\subsection{FT-IR Instrumentation and Spectra Collection}

FT-IR measurements were carried out on all the samples using a Perkin-Elmer FT-IR Spectrometer Spectrum GX1, covering the IR spectral range from 4000 to $950 \mathrm{~cm}^{-1}$. A small amount of each sample was dropped onto the centre of the $\mathrm{NaCl}$ plates $(2 \mathrm{~mm}$ thick, $25 \mathrm{~mm}$ diameter) and air-dried for $20 \mathrm{~min}$ for infrared analysis in transmission mode. Each spectrum was the result of 64 scans with a spectral resolution of $4 \mathrm{~cm}^{-1}$. A background spectrum was collected before each acquisition, acquired on clean $\mathrm{NaCl}$ salt plate, and ratioed against the sample spectrum. The experiments were carried out at room temperature: i.e., $25 \pm 2{ }^{\circ} \mathrm{C}$. For all the samples, the average spectra were calculated $(n=5)$. Raw FT-IR spectra were converted in absorbance and 2-points baseline corrected.

\subsection{Data Processing}

In order to perform an unsupervised analysis, all the FT-IR spectral data in the spectral range 1180-950 $\mathrm{cm}^{-1}$ [23-25] were corrected according to standard normal variation (SNV), second derivative transformed (DII, 9-point smoothing), mean-centred, and then submitted to Principal Component Analysis. The analysis was used to reduce the entire spectral data 
set to a small number of latent variables or principal components (PCs) accounting for IR attributes.

An analogous elaboration was performed on UV-Vis spectra recorded from 250 to $700 \mathrm{~nm}$ on samples diluted in acidic media (treatment " $\mathrm{HCl}^{\prime \prime}$ ) to reduce the entire spectral data set to a small number of latent variables accounting for UV-Vis attributes: in this case, data were only normalised.

The scores of the first three coordinates resulted for each sample from the analysis of FT-IR (PC_FTIR) and UV-Vis (PC_UVVis) spectra were then processed using multivariate chemometric techniques involving cluster analysis (CA) and principal component analysis (PCA).

\subsection{Statistical Analysis}

Appropriate controls were carried out throughout all the experiments described above. The data reported for TPC, TFC, TAC, and TAA represent average values from at least three independent experiments, each performed in duplicate, and the results were expressed as mean with standard deviation (SD). Sour cherry samples were also classified according to the area of production declared on the commercial label (see Supplementary Materials Table S1). Statistical differences were obtained through an analysis of variance (ANOVA) followed by Tukey's multiple comparison test at 95\% confidence level $(p \leq 0.05)$. The normality of the data set was checked with the Jarque-Bera test, and the outliers were determined with the Grubbs test.

UV-Vis spectroscopic measurements were performed in duplicate and averaged at each pin number to produce a single sample spectrum.

Statistical treatments were performed using XLSTAT 2018.5 software (Addinsoft Inc., New York, NY, USA).

Multivariate statistical treatments were performed using Pirouette 4.5 software (InfometrixCorp., Bothell, WA, USA) for FT-IR data and XLSTAT 2018.5 software (Addinsoft Inc., New York, NY, USA) for UV-Vis and PCs data.

\section{Results}

Total antioxidant activity (TAA) using the ABTS assay, total phenolic content (TPC), total flavonoid content (TFC), total anthocyanins content (TAC), and colour parameters, together with spectroscopic data (FT-IR and UV-Vis) of several samples of fruit drinks and red wines, were measured, with the aim of understanding a possible relationship between composition, production area, and antioxidant properties. For sour cherry drinks, particular attention was devoted to any differences between the samples produced with the two different techniques typical of the provinces of Ancona and Pesaro-Urbino.

\subsection{Total Antioxidant Activity Level, Total Polyphenols, Flavonoids and Anthocyanin Content}

Total antioxidant activity using the ABTS assay (TAA), total phenolic content (TPC), total flavonoid content (TFC), and total anthocyanins content (TAC) of all samples are reported in Table 1.

The values obtained from the analysis of the antioxidant activity (TAA) of the samples range from 13 to $30 \mathrm{mM}$ TE for the fruit's spirits: sour cherry samples SCW15 and SCW01 (13 mM TE) have the lower antioxidant activity values, while SCW06 (28 mM TE) and CL (30 mM TE) have the higher. Values measured for red wines are the highest among all the samples (31-35 mM TE).

The total phenol contents (TPC) of the samples were measured using Folin-Ciocalteu's reagent reported in Table 1 are also graphically displayed in Figure 1.

The amount of total phenolics in the samples range between 6.9 and $16.3 \mathrm{mM}$ GAE and agree with data from the literature [23-27]. Sour cherry sample SCW15 (6.9 mM GAE) and black cherry liquor BCL (7.9 mM GAE) contain the lowest amounts of phenolic compounds, while SCW06 (16.3 mM GAE) and CL cherry liquor (16.1 mM GAE) show the highest TPC values. 
Table 1. Total antioxidant activity using the ABTS assay (TAA), total phenolic content (TPC), total flavonoid content (TFC), and total anthocyanins content (TAC) of all samples.

\begin{tabular}{ccccc}
\hline Sample & $\begin{array}{c}\text { TAA } \\
\text { mM TE }\end{array}$ & $\begin{array}{c}\text { TPC } \\
\text { mM GAE }\end{array}$ & $\begin{array}{c}\text { TFC } \\
\text { mM CE }\end{array}$ & $\begin{array}{c}\text { TAC } \\
\text { mg/L }\end{array}$ \\
\hline SCW01 & $13 \pm 4$ & $8.7 \pm 1.1$ & $3.4 \pm 0.3$ & $12 \pm 3$ \\
SCW02 & $16 \pm 2$ & $9.7 \pm 1.1$ & $3.5 \pm 0.2$ & $24 \pm 7$ \\
SCW03 & $17 \pm 2$ & $10.1 \pm 0.7$ & $3.2 \pm 0.2$ & $41 \pm 7$ \\
SCW04 & $18 \pm 3$ & $10.2 \pm 0.9$ & $3.2 \pm 0.2$ & $52 \pm 8$ \\
SCW05 & $18 \pm 1$ & $9.1 \pm 0.4$ & $3.5 \pm 0.4$ & $31 \pm 5$ \\
SCW06 & $28 \pm 2$ & $16.3 \pm 0.6$ & $5.7 \pm 0.3$ & $41 \pm 6$ \\
SCW07 & $21 \pm 2$ & $14.4 \pm 1.0$ & $5.9 \pm 0.4$ & $41 \pm 4$ \\
SCW08 & $25 \pm 1$ & $14.2 \pm 0.9$ & $5.4 \pm 0.3$ & $39 \pm 7$ \\
SCW09 & $14 \pm 2$ & $8.4 \pm 0.2$ & $3.0 \pm 0.2$ & $22 \pm 4$ \\
SCW10 & $18 \pm 3$ & $9.9 \pm 0.4$ & $3.1 \pm 0.2$ & $51 \pm 8$ \\
SCW11 & $22 \pm 3$ & $11.8 \pm 0.9$ & $4.3 \pm 0.2$ & $44 \pm 3$ \\
SCW12 & $25 \pm 2$ & $13.6 \pm 0.2$ & $4.7 \pm 0.3$ & $67 \pm 4$ \\
SCW13 & $27 \pm 1$ & $14.2 \pm 1.1$ & $4.9 \pm 0.2$ & $89 \pm 4$ \\
SCW14 & $24 \pm 4$ & $13.4 \pm 1.0$ & $4.8 \pm 0.2$ & $26 \pm 5$ \\
SCW15 & $13 \pm 2$ & $6.9 \pm 0.6$ & $2.1 \pm 0.1$ & $18 \pm 2$ \\
BW & $20 \pm 2$ & $13.1 \pm 1.0$ & $5.5 \pm 0.5$ & $18 \pm 3$ \\
BCL & $14 \pm 2$ & $7.9 \pm 0.6$ & $2.8 \pm 0.2$ & $16 \pm 4$ \\
CL & $30 \pm 2$ & $16.1 \pm 0.7$ & $5.9 \pm 0.6$ & $72 \pm 4$ \\
W01 & $31 \pm 1$ & $14.3 \pm 0.5$ & $5.6 \pm 0.3$ & $174 \pm 6$ \\
W02 & $31 \pm 2$ & $13.1 \pm 0.7$ & $5.2 \pm 0.3$ & $178 \pm 6$ \\
W03 & $35 \pm 3$ & $15.1 \pm 1.1$ & $5.7 \pm 0.3$ & $208 \pm 8$ \\
\hline SCW(PU) & $19 \pm 5^{\mathrm{B}}$ & $11.6 \pm 2.9^{\mathrm{A}}$ & $4.2 \pm 1.2^{\mathrm{A}}$ & $35 \pm 12^{\mathrm{B}}$ \\
SCW(AN) & $21 \pm 5^{\mathrm{B}}$ & $11.6 \pm 2.4^{\mathrm{A}}$ & $4.0 \pm 0.9^{\mathrm{A}}$ & $55 \pm 25^{\mathrm{B}}$ \\
W & $32 \pm 2^{\mathrm{A}}$ & $14.1 \pm 1.0^{\mathrm{A}}$ & $5.5 \pm 0.3^{\mathrm{A}}$ & $187 \pm 18^{\mathrm{A}}$ \\
\hline
\end{tabular}

Results are expressed as mean values \pm standard deviation $(n=3)$. Superscript letters within each column indicate homogeneous sub-classes resulting from Tukey's post hoc multiple comparison test $(p<0.01)$.

Samples belonging to the different areas do not show significatively different mean values (AN: $11.6 \pm 2.4$; PU: $11.6 \pm 2.9 \mathrm{mM} \mathrm{GAE}$ ), while red grape wines show high TPC values $(14.1 \pm 1.0 \mathrm{mM}$ GAE) comparable to those of the highest sour cherry samples.

Total flavonoids content (TFC) values range from 2.1 to $5.8 \mathrm{mM} \mathrm{CE}$ for sour cherry samples and from 5.2 to $5.7 \mathrm{mM} \mathrm{CE}$ for red grape wines and agree with the literature reports [23,28,29]. Liquors ranged from 2.7 to $5.8 \mathrm{mM} \mathrm{CE}$.

Total monomeric anthocyanin content (TAC) expressed as $\mathrm{mg} / \mathrm{L}$ cyanidine-3-glucoside determined with the $\mathrm{pH}$-differential method varies from 12 to $89 \mathrm{mg} / \mathrm{L}$ in sour cherry samples. Among these samples, SCW01 contains the lowest amounts of anthocyanins, whereas the highest TAC value was found for SCW13.

The total antioxidant activity trend was compared to data obtained from the quantifications of the main phytochemicals present in the samples showing good and significant correlations between TAA and TPC, TFC and TAC $(r=0.887,0.849$ and 0.815 , respectively; $p<0.0001)$, and confirming that all the different classes of phytochemicals contribute to the "in vitro" antioxidant activity. In addition, total flavonoids content (TFC) correlate well with TPC $(\mathrm{r}=0.962$ and $p=0.0000)$, confirming that flavonoids constitute the most abundant group of polyphenols in red wines [30] and sour cherries [8], but anthocyanins do not correlate with phenols and flavonoids $(\mathrm{r}=0.502$ and $0.503 ; p=0.02)$ : in fact, all the red wines show a much higher content of anthocyanins $(187 \mathrm{mg} / \mathrm{L})$ than all berry samples, and these values agree with literature reports [31]. 


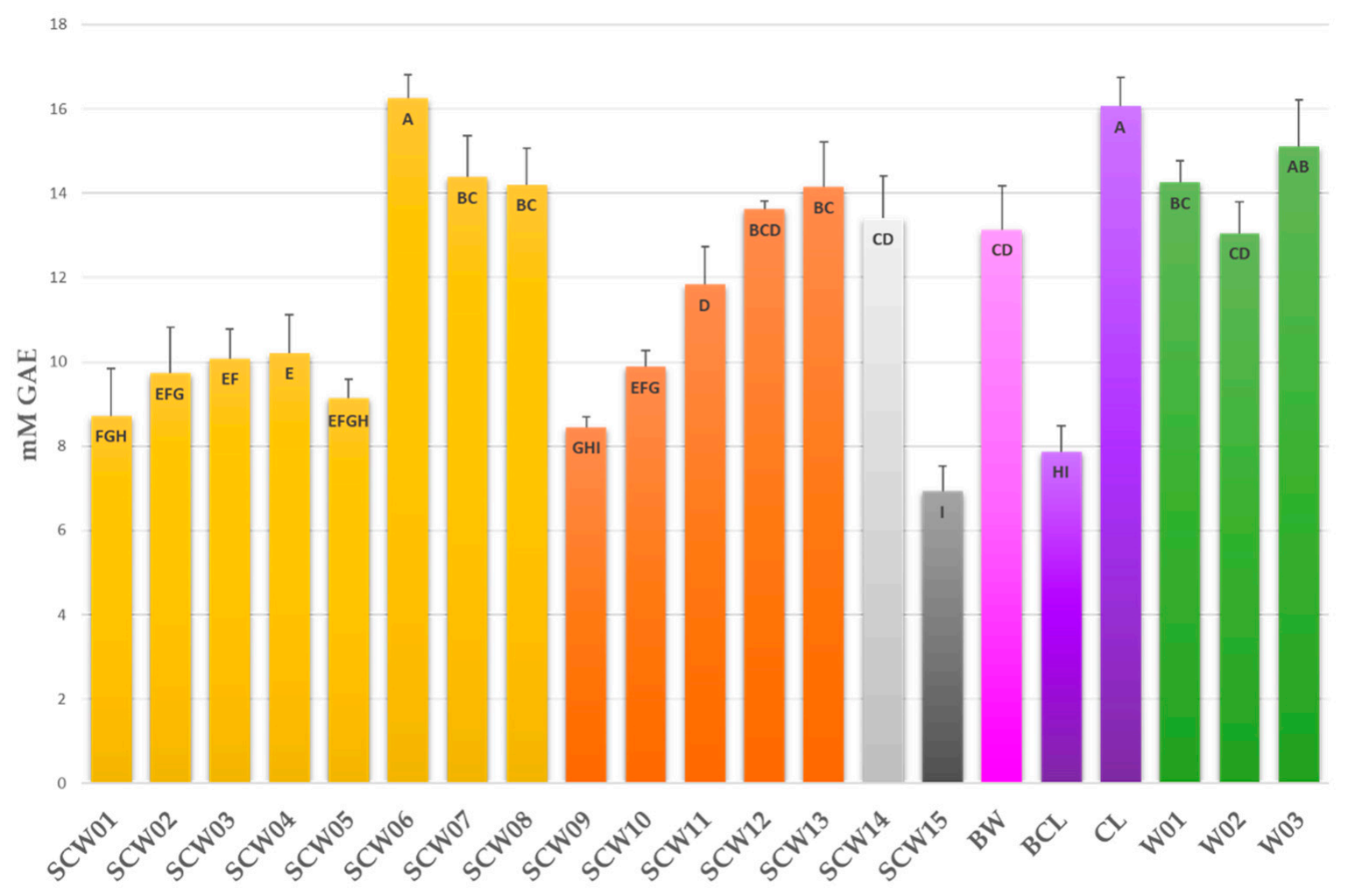

Figure 1. Total phenol contents (TPC) of the samples measured using Folin-Ciocalteu's reagent. Bars are coloured depending on the province (yellow $=\mathrm{PU}$; orange $=\mathrm{AN}$; light grey $=\mathrm{MC}$; grey $=\mathrm{AP}$ ) and on the type of the contained berry (yellow, orange, light grey, and grey = sour cherry; pink = blackthorn; violet = cherry; green = grape). Letters in the bars indicate homogeneous sub-classes resulting from Tukey's post hoc multiple comparison test $(p<0.01)$.

\subsection{Evaluation of Colour Parameters of Samples}

Colour parameters for the beverages studied were determined following the modified Somers assay [22] and are reported in Table 2.

Colour density and hue, calculated using the absorbance of the sample at 420 (yellow/orange pigments) and $520 \mathrm{~nm}$ (red pigments) in its standardised original state, are routinely used in the wine industry to quantify the visual appearance of wine; strong positive correlations are usually [32] found between colour density and wine quality. Sour cherry samples show colour density values ranging from 5.6 to $14.6 \mathrm{au}$ ) with a significant correlation with TAA, TPC, and TFC $(\mathrm{r}=0.482,0.607$ and 0.545 , respectively; $p<0.05)$ and hue values ranging from 0.68 and 1.25 that inversely correlate with TAC $(\mathrm{r}=-0.534$; $p=0.013$ ).

The two spectral ratios referred to as the "chemical age" express the extent to which polymeric pigment forms displaced the monomers (anthocyanins) during ageing reactions, since the polymeric pigments are artefacts of the wine making process and of subsequent conservation. Chemical Age 1 and 2 increase during ageing and as expected, for sour cherry samples aged at least six months, these parameters are in the ranges from 0.59 to 0.84 and from 0.26 to 0.57 , respectively; however, for red wines, lower values $(0.4-0.5$ and $0.01-0.13$, respectively) were obtained. As expected, these parameters inversely correlate with TAC $(\mathrm{r}=-0.818$ and $-0.854 ; p<0.0001)$.

Analysis of the samples diluted with $1 \mathrm{M}$ hydrochloric acid, which lowers the $\mathrm{pH}$ and converts all anthocyanins and many other pigments into their coloured forms, gives an indication of the concentration of total red pigments and total phenolics. These acidified solutions were monitored at 520 and $280 \mathrm{~nm}$, and as expected, it was found that the two measured parameters correlate with TAC $(r=0.993 ; p<0.0001)$ and TPC $(r=0.947$; $p<0.0001)$, respectively. 
Table 2. Colour parameter calculated for all samples.

\begin{tabular}{|c|c|c|c|c|c|c|c|}
\hline Sample & Area & Colour Density & Hue & Chemical Age 1 & Chemical Age 2 & Total Anthocyanins & Total Phenolics \\
\hline SCW01 & PU & 7.9 & 1.25 & 0.84 & 0.53 & 24.8 & 46.3 \\
\hline SCW02 & PU & 8.3 & 1.02 & 0.82 & 0.51 & 32.4 & 48.1 \\
\hline SCW03 & PU & 7.2 & 0.80 & 0.63 & 0.31 & 89.6 & 43.7 \\
\hline SCW04 & PU & 8.8 & 0.76 & 0.59 & 0.27 & 134.4 & 47.8 \\
\hline SCW05 & PU & 8.8 & 0.89 & 0.71 & 0.41 & 81.1 & 54.4 \\
\hline SCW06 & PU & 13.3 & 0.99 & 0.80 & 0.44 & 86.8 & 77.7 \\
\hline SCW07 & PU & 14.4 & 0.80 & 0.79 & 0.44 & 108.1 & 79.8 \\
\hline SCW08 & PU & 13.9 & 0.68 & 0.78 & 0.44 & 105.6 & 69.1 \\
\hline SCW09 & $\mathrm{AN}$ & 6.9 & 0.87 & 0.71 & 0.35 & 76.5 & 45.1 \\
\hline SCW10 & $\mathrm{AN}$ & 10.6 & 0.75 & 0.66 & 0.32 & 133.3 & 43.7 \\
\hline SCW11 & $\mathrm{AN}$ & 14.6 & 0.77 & 0.76 & 0.40 & 130.7 & 61.5 \\
\hline SCW12 & AN & 10.8 & 0.89 & 0.66 & 0.26 & 191.1 & 64.6 \\
\hline SCW13 & $\mathrm{AN}$ & 12.3 & 0.68 & 0.68 & 0.27 & 228.9 & 69.9 \\
\hline SCW14 & $\mathrm{MC}$ & 9.2 & 0.83 & 0.83 & 0.43 & 73.1 & 67.8 \\
\hline SCW15 & $\mathrm{AP}$ & 5.6 & 0.97 & 0.64 & 0.32 & 63.1 & 31.5 \\
\hline BW & & 4.9 & 1.09 & 0.71 & 0.33 & 53.5 & 73.4 \\
\hline BCL & & 10.4 & 1.14 & 0.70 & 0.57 & 23.1 & 47.0 \\
\hline CL & & 13.0 & 0.73 & 0.69 & 0.33 & 165.8 & 80.3 \\
\hline W01 & & 11.2 & 0.79 & 0.51 & 0.13 & 409.4 & 76.5 \\
\hline W02 & & 8.3 & 0.70 & 0.47 & 0.09 & 448.5 & 67.0 \\
\hline W03 & & 10.3 & 0.74 & 0.44 & 0.09 & 559.6 & 85.5 \\
\hline
\end{tabular}

\subsection{Chemometric Analysis of Spectroscopic Data}

To investigate the composition of the alcoholic beverages studied, FT-IR and UVVis spectroscopic measurements were carried out. The obtained data were statistically processed by principal component analysis (PCA) as multivariate data methods with the Pearson correlation coefficient as the index of similarity between variables.

\subsubsection{FT-IR Spectra}

Normalised PCA analysis (Figure S1) was performed on the 2nd derivative in the $950-1200 \mathrm{~cm}^{-1}$ region of the FT-IR spectra of the samples [15], and results in a model with the first two PCs explain 98\% of variation in the spectra (PC1 $=87 \%, \mathrm{PC} 2=7 \%, \mathrm{PC} 3=4 \%$ ). Examination of the PCA score plot of the first two coordinates shows that it is not possible to adequately discriminate between drinks produced from different berries and/or from different areas, and that only red wines separate from the other samples. The eigenvectors of the three first PCs indicates that the bands contributing most to the separation of the samples are those in the range below 1000 and upper $1100 \mathrm{~cm}^{-1}$. This model was used to reduce the data dimension and to extrapolate three new variables (PC_FTIR), maximising similarities among samples, and to have a first evaluation of the classificatory efficiency of the variables considered.

\subsubsection{UV-VIS Spectra}

For UV-Vis spectra, the PCA analysis was performed on the UV-Vis spectra of samples diluted in acid media (Treatment " $\mathrm{HCl}^{\prime}$ ) and the resulting first three component explain $96 \%$ of variation in the spectra ( $\mathrm{PC} 1=61 \%, \mathrm{PC} 2=21 \%$, $\mathrm{PC} 3=15 \%$ ). As can be seen (Supplementary Materials Figure S2) from the score plot (a) and associated eigenvector (b) resulting from the analysis, red wines (green) were sufficiently discriminated from the other samples, but it was not possible to discriminate between SCW produced in different areas, and other fruit samples (CL, BCL, and BW). However, examination of the PCA graph in comparison with antioxidant experimental data reveal that all the SCW samples located on the left have a low antioxidant activity (red $\leq 18 \mathrm{mM} \mathrm{TE}$ ), whereas the SCW samples located on the right have high TAA values (blue $\geq 21 \mathrm{mM} \mathrm{TE}$ ) showing that UV-Vis data can help to individuate samples with high antioxidant activity. The eigenvectors of the 
three first PCs indicates that bands at 270 and $370-590 \mathrm{~cm}^{-1}$ (PC1); 255, 300, 370, and $520 \mathrm{~cm}^{-1}$ (PC2); and 290-350 $\mathrm{cm}^{-1}$ (PC3) are those with the greater variance among the different types of beverages.

This analysis allows us to reduce the UV-Vis data set and to extrapolate three new coordinates (PC_UVVis) maximising similarities among samples and that were then used for whole data set elaboration.

\section{Discussion}

The results obtained in the present study indicate that production area, type of cherries or wine, and procedure used to make the alcoholic beverages have no effect on their antioxidant properties. In fact, sour cherry beverages produced in the PU province show mean values for TAA lower than, but not significantly different from, those of the Ancona area (see Table 1); moreover, the variability of the "in vitro" antioxidant activity between the samples of the two areas is the same. The same trend is also obtained by analysing the TPC and TFC values. On the other hand, the analysis of the results obtained from the TAC measurements permits us to make some consideration of the ageing of the different samples. Red grape wines show a mean value significantly lower than that of PU and AN sour cherry samples $(p<0.0001)$; the mean PU value is lower than that of AN. If the different methods used in the two areas to produce the beverage are considered, it can be stated that the longer ageing of the wine used in the PU province yields a decrease in the anthocyanins content of these beverages. This hypothesis is also supported by the significantly higher anthocyanins content measured for grape red wines that are not aged. In addition, chemical ages (CA) that measure the polymeric pigment formed from monomeric anthocyanins during ageing reactions show an inverse correlation with TAC $(\mathrm{r}=-0.825$ and -0.8541 for CA1 and CA2, respectively; $p<0.0001)$, and monomeric anthocyanins ( $\mathrm{r}=0.993 ; p<0.0001)$, more present in young wines (see Results).

\section{Statistical Elaboration of Whole Data Set}

Although PCA itself cannot be used as a classification tool, it can indicate a trend that is relevant for visualising the dimension of the space. With this aim, the first three coordinates obtained from the PCA analysis of the FT-IR spectra (PC_FTIR) and the first three coordinates obtained from the PCA analysis of the UV-Vis spectra in $\mathrm{HCl}$ solutions (PC_UVVis), were statistically elaborated by performing a principal component analysis using the covariance as the index of similarity between variables. The score plot resulting from the analysis and displayed in Figure 2 shows that the first two factors (F) explain $95.2 \%$ of variation in the spectra $(\mathrm{F} 1=75.4 \%, \mathrm{~F} 2=19.8 \%)$ and discriminate well between $\mathrm{W}$, SCW with high (H) and low (L) antioxidant activity, and BW (B), whereas liquors (CL) are arranged following their antioxidant activity rather than the type of cherry.

The eigenvectors of the first three factors reported in Table 3 show that the FT-IR coordinates contribute very little to the separation of the samples, and it is especially UVVis variables that give an important contribution to the determination of the antioxidant potential of the samples.

In addition, a cluster analysis (CA) was applied to determine whether the data set could be divided into groups to explain the scale and relationship of the different type of samples analysed. The similarities between the samples were determined based on their Euclidean distance, and the objects were clustered using Ward's method.

The CA dendrogram displayed in Figure 3 shows that three main clusters were suggested. The first group consisted of SCW samples with high antioxidant activity $(\mathrm{H})$, the second group of SCW with low antioxidant activity (L), and the third consisted of red wines. In addition, one of the CL sample and BW sample were separated from all other beverages. 


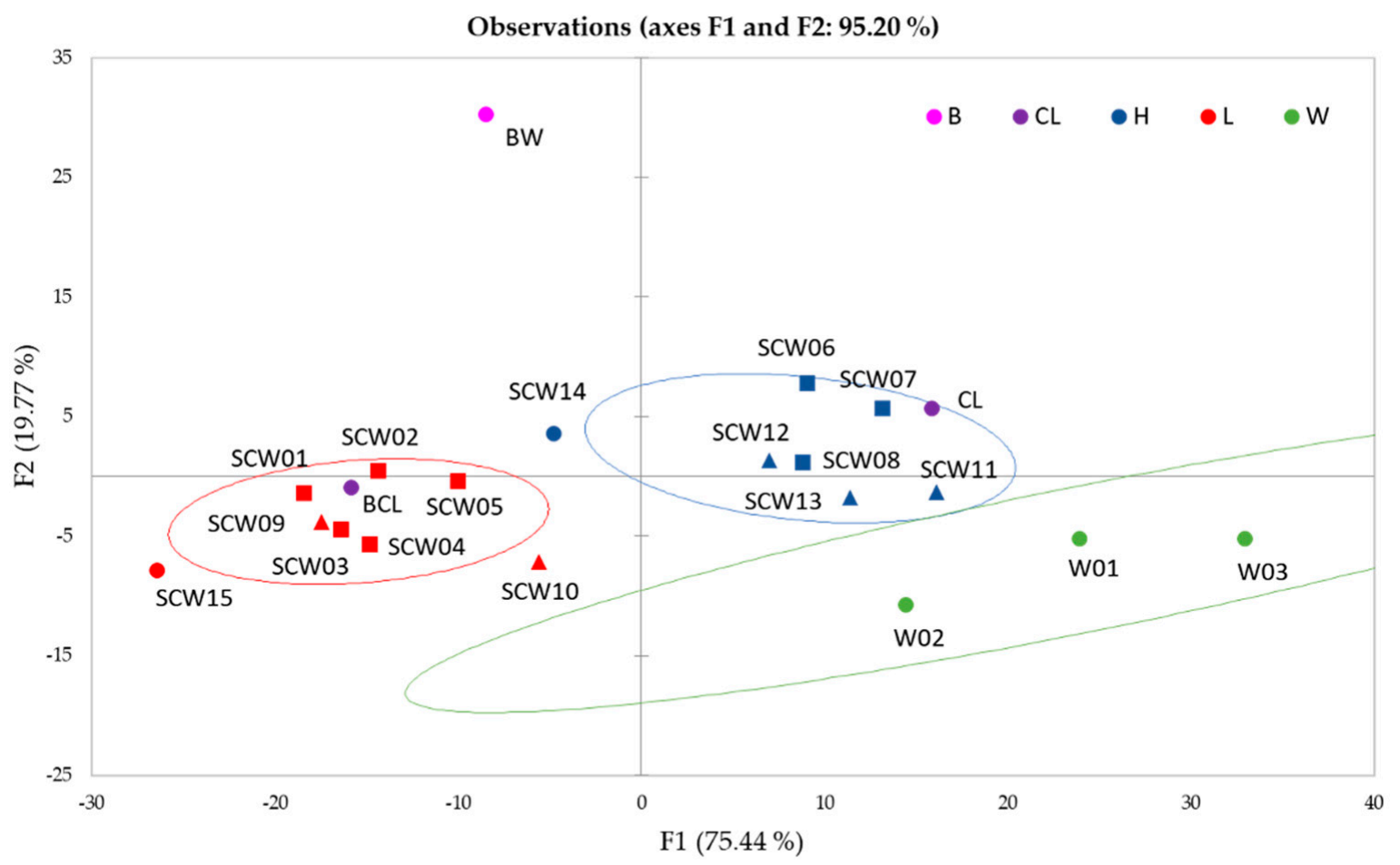

Figure 2. Score plot for the first two factors resulted from the principal component analysis performed using the data set consisting of the first three coordinates (PC_FTIR) obtained from the analysis of the FT-IR spectra and of the UV-Vis spectra in $\mathrm{HCl}$ solutions. Points are coloured depending on the type of the contained berry and on the TAA level: (red = sour cherry with low TAA; blue = sour cherry with high TAA; pink = blackthorn; violet = cherry liquors; green = grape wine) and shaped depending on the production area (square $=\mathrm{PU}$; triangle $=\mathrm{AN})$.

Table 3. Eigenvalues, explained (Variability \%) and cumulative variance (Cumulative \%), and eigenvectors for the first three factors $(\mathrm{F})$ obtained with principal component analysis performed on the data set consisting of the first three coordinates (PC_FTIR) obtained from the FT-IR spectra and the first three coordinates (PC_UVVis) obtained from the UV-Vis spectra in $\mathrm{HCl}$ solutions.

\begin{tabular}{cccc}
\hline & F1 & F2 & F3 \\
\hline Eigenvalue & 257.119 & 67.382 & 16.325 \\
Variability (\%) & 75.436 & 19.769 & 4.790 \\
Cumulative \% & 75.436 & 95.205 & 99.994 \\
Eigenvectors & & & \\
PC_FTIR1 & 0.005 & -0.009 & -0.024 \\
PC_FTIR2 & 0.000 & 0.000 & 0.000 \\
PC_FTIR3 & 0.001 & -0.001 & -0.003 \\
PC_UVVis1 & 1.000 & 0.000 & 0.000 \\
PC_UVVis2 & 0.000 & 1.000 & 0.000 \\
PC_UVVis3 & 0.000 & 0.000 & 1.000 \\
\hline
\end{tabular}

\section{Conclusions}

In this paper, several samples of sour cherry spirits produced in the Marche region with different typical recipes were studied to evidence the beneficial properties of these beverages and to correlate this feature to the different techniques utilised for the production.

The results showed that the production area, the recipe, and the type of cherries used to make the alcoholic beverage do not influence the antioxidant properties and the phytochemical contents of the samples.

Moreover, high "in vitro" antioxidant activity values were measured for sour cherry beverages that can be ascribed more to flavonoids than to anthocyanin's content. 
In addition, the multivariate treatment allowed us to differentiate samples with high antioxidant activity using easy and low-cost instrumental techniques that require little time and can be employed in routine analysis.

In conclusion, the characterisation of antioxidant activity and colour of this typical beverage widespread in the Marche region could be used to promote the production and the commercialisation of this traditional product.

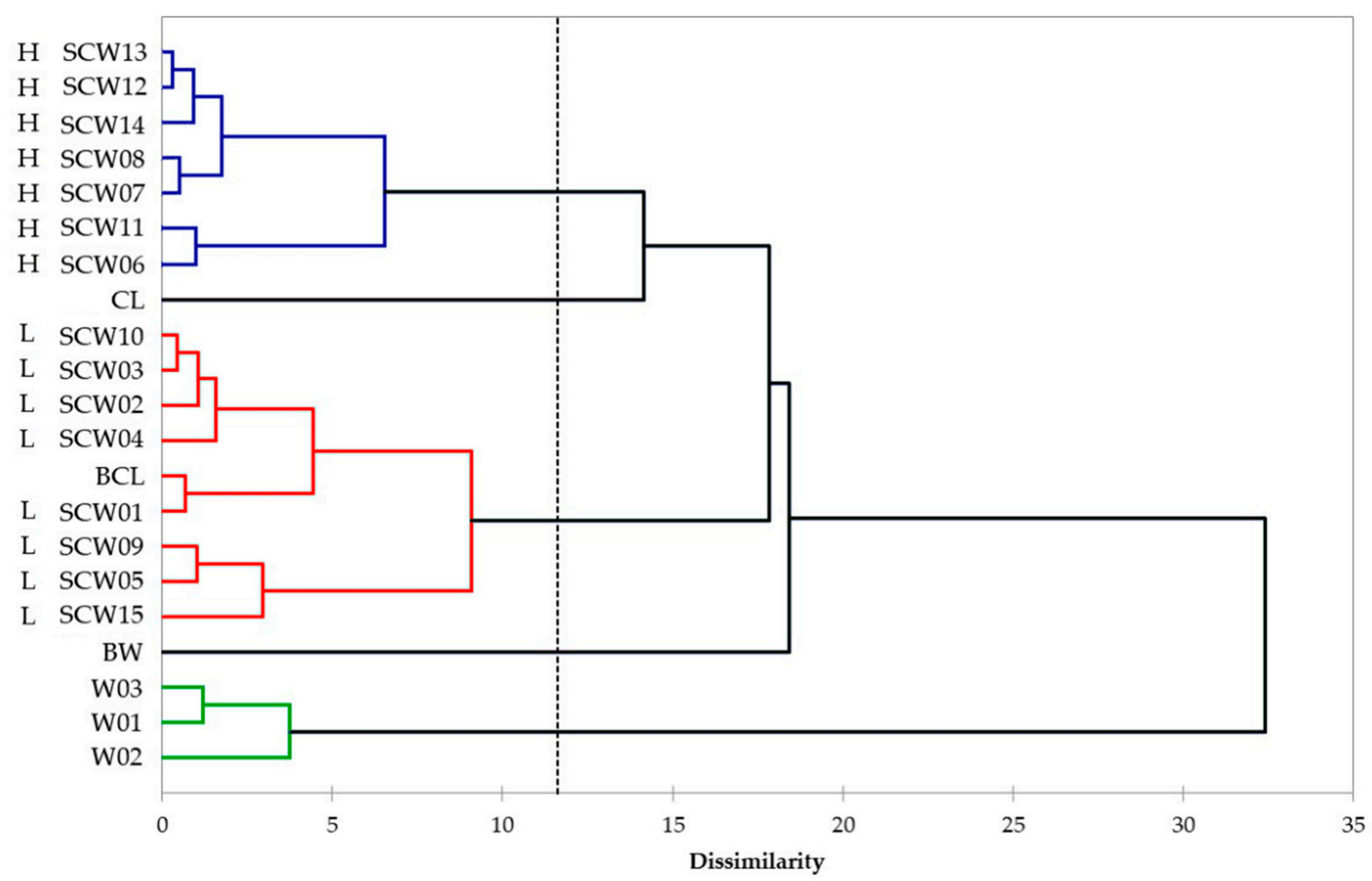

Figure 3. Dendrogram obtained by cluster analysis performed using Ward's method (Euclidean distance) on the data set incorporating all samples and six variables (PCs_FTIR and PCs_UVVis). SCW samples are described by their acronym and their antioxidant activity level as L and H. Groups are coloured depending on the type of beverage and on the TAA level: (red = sour cherry with low TAA; blue = sour cherry with high TAA; green = grape wine).

Supplementary Materials: The following are available online at https:/ /www.mdpi.com/article/10 .3390 / foods10081953/s1. Table S1. Description of the samples. Figure S1. Score plot (a) for the first two PCs, eigenvector (b) and eigenvalue (c) resulted from the PCA analysis performed on the 2nd derivative of the $950-1180 \mathrm{~cm}^{-1}$ region of the FT-IR spectra of the samples. Figure S2. Score plot (a) for the first two PCs, eigenvector (b) and eigenvalue (c) resulted from the PCA analysis performed on the UV-Vis spectra of samples diluted in acid media (Treatment " $\mathrm{HCl}^{\prime}$ ).

Author Contributions: Conceptualization, P.C. and M.P.; methodology, M.P., S.S. and P.A.; formal analysis, P.A. and S.S.; Data curation, P.A. and S.S.; writing-original draft preparation, P.C.; writingreview and editing, P.C.; M.P., P.A. and S.S. All authors have read and agreed to the published version of the manuscript.

Funding: This research received no external funding.

Institutional Review Board Statement: Not applicable.

Informed Consent Statement: Not applicable.

Data Availability Statement: Data is contained within the article or Supplementary Materials.

Conflicts of Interest: The authors declare no conflict of interest. 


\section{References}

1. Van de Kop, P.; Sautier, D.; Gerz, A. Origin-Based Products: Lessons for Pro-Poor Market Development; KIT: Amsterdam, The Netherlands, 2006; Volume 372.

2. Bearth, A.; Cousin, M.-E.; Siegrist, M. The consumer's perception of artificial food additives: Influences on acceptance, risk and benefit perceptions. Food Qual. Prefer. 2014, 38, 14-23. [CrossRef]

3. Tiozzo, B.; Mari, S.; Ruzza, M.; Crovato, S.; Ravarotto, L. Consumers' perceptions of food risks: A snapshot of the italian triveneto area. Appetite 2017, 111, 105-115. [CrossRef]

4. Kaur, C.; Kapoor, H.C. Antioxidants in fruits and vegetables-The millennium's health. Int. J. Food Sci. Technol. 2001, 36, 703-725. [CrossRef]

5. Deliberazione Della Giunta Regionale. Prodotti di Qualità e Certificazione-Prodotti Tradizionali. 2019. Available online: www.regione.marche.it/Regione-Utile/Agricoltura-Sviluppo-Rurale-e-Pesca/Prodotti-di-qualit\%C3\%A0-e-certificazione\# Prodotti-Tradizionali (accessed on 10 July 2021).

6. Guilford, J.M.; Pezzuto, J.M. Wine and health: A review. Am. J. Enol. Vitic. 2011, 62, 471. [CrossRef]

7. Cásedas, G.; Les, F.; Gómez-Serranillos, M.P.; Smith, C.; López, V. Bioactive and functional properties of sour cherry juice (prunus cerasus). Food Funct. 2016, 7, 4675-4682. [CrossRef] [PubMed]

8. Ferretti, G.; Bacchetti, T.; Belleggia, A.; Neri, D. Cherry antioxidants: From farm to table. Molecules 2010, 15, 6993-7005. [CrossRef]

9. Khoo, G.M.; Clausen, M.R.; Pedersen, B.H.; Larsen, E. Bioactivity and total phenolic content of 34 sour cherry cultivars. J. Food Compos. Anal. 2011, 24, 772-776. [CrossRef]

10. Wojdyło, A.; Nowicka, P.; Laskowski, P.; Oszmiański, J. Evaluation of sour cherry (prunus cerasus 1.) fruits for their polyphenol content, antioxidant properties, and nutritional components. J. Agric. Food Chem. 2014, 62, 12332-12345. [CrossRef]

11. Kim, D.-O.; Heo, H.J.; Kim, Y.J.; Yang, H.S.; Lee, C.Y. Sweet and sour cherry phenolics and their protective effects on neuronal cells. J. Agric. Food Chem. 2005, 53, 9921-9927. [CrossRef] [PubMed]

12. Kirakosyan, A.; Mitchell Seymour, E.; Noon, K.R.; Urcuyo Llanes, D.E.; Kaufman, P.B.; Warber, S.L.; Bolling, S.F. Interactions of antioxidants isolated from tart cherry (prunus cerasus) fruits. Food Chem. 2010, 122, 78-83. [CrossRef]

13. Castiglioni, S.; Stefano, M.; Pisani, M.; Carloni, P. Geographical characterisation of multifloral honeys from the marche region (italy) according to their antioxidant activity and colour using a chemometric approach. Int. J. Food Sci. Technol. 2018, 53, 571-581. [CrossRef]

14. Parpinello, G.P.; Ricci, A.; Arapitsas, P.; Curioni, A.; Moio, L.; Riosegade, S.; Ugliano, M.; Versari, A. Multivariate characterisation of italian monovarietal red wines using mir spectroscopy: This article is published in cooperation with the 11th oenoivas international symposium, 25-28 June 2019, Bordeaux, France. OENO One 2019, 53, 168. [CrossRef]

15. Zhang, Y.-L.; Chen, J.-B.; Lei, Y.; Zhou, Q.; Sun, S.-Q.; Noda, I. Discrimination of different red wine by fourier-transform infrared and two-dimensional infrared correlation spectroscopy. J. Mol. Struct. 2010, 974, 144-150. [CrossRef]

16. Castiglioni, S.; Astolfi, P.; Conti, C.; Monaci, E.; Stefano, M.; Carloni, P. Morphological, physicochemical and ftir spectroscopic properties of bee pollen loads from different botanical origin. Molecules 2019, 24, 3974. [CrossRef]

17. Deliberazione Della Giunta Regionale. Schede Prodotti Tradizionali Regione Marche. 2017. Available online: https: / / www.regione.marche.it/Portals / / Agricoltura/qualita/Prodotti\%20Tradizionali/Schede\%20prodotti\%20tradizionali\%20 regione\%20Marche\%202017.pdf (accessed on 10 July 2021).

18. Pellegrini, N.; Ke, R.; Yang, M.; Rice-Evans, C. [34] screening of dietary carotenoids and carotenoid-rich fruit extracts for antioxidant activities applying 2,2'-azinobis(3-ethylenebenzothiazoline-6-sulfonic acid radical cation decolorization assay. In Methods in Enzymology; Packer, L., Ed.; Academic Press: New York, NY, USA; London, UK, 1999; Volume 299 , pp. $379-389$.

19. Singleton, V.L.; Orthofer, R.; Lamuela-Raventos, R.M. Analysis of total phenols and other oxidation substrates and antioxidants by means of folin-ciocalteu reagent. In Methods in Enzymology; Packer, L., Ed.; Academic Press: New York, NY, USA; London, UK, 1999; Volume 299, pp. 152-178.

20. Gursoy, N.; Sarikurkcu, C.; Cengiz, M.; Solak, M.H. Antioxidant activities, metal contents, total phenolics and flavonoids of seven morchella species. Food Chem. Toxicol. 2009, 47, 2381-2388. [CrossRef]

21. Giusti, M.M.; Wrolstad, R.E. Characterization and measurement of anthocyanins by uv-visible spectroscopy. Curr. Protoc. Food Anal. Chem. 2001, F1.2.1-F1.2.13. [CrossRef]

22. Mercurio, M.D.; Dambergs, R.G.; Herderich, M.J.; Smith, P.A. High throughput analysis of red wine and grape phenolicsadaptation and validation of methyl cellulose precipitable tannin assay and modified somers color assay to a rapid 96 well plate format. $J$. Agric. Food Chem. 2007, 55, 4651-4657. [CrossRef]

23. Garaguso, I.; Nardini, M. Polyphenols content, phenolics profile and antioxidant activity of organic red wines produced without sulfur dioxide/sulfites addition in comparison to conventional red wines. Food Chem. 2015, 179, 336-342. [CrossRef]

24. Heinonen, I.M.; Lehtonen, P.J.; Hopia, A.I. Antioxidant activity of berry and fruit wines and liquors. J. Agric. Food Chem. 1998, 46, 25-31. [CrossRef]

25. Silva, S.D.; Feliciano, R.P.; Boas, L.V.; Bronze, M.R. Application of ftir-atr to moscatel dessert wines for prediction of total phenolic and flavonoid contents and antioxidant capacity. Food Chem. 2014, 150, 489-493. [CrossRef]

26. Staško, A.; Brezová, V.; Mazúr, M.; Čertík, M.; Kaliňák, M.; Gescheidt, G. A comparative study on the antioxidant properties of slovakian and austrian wines. LWT Food Sci. Technol. 2008, 41, 2126-2135. [CrossRef] 
27. Versari, A.; Parpinello, G.P.; Scazzina, F.; Rio, D.D. Prediction of total antioxidant capacity of red wine by fourier transform infrared spectroscopy. Food Control 2010, 21, 786-789. [CrossRef]

28. Pimentel, F.A.; Nitzke, J.A.; Klipel, C.B.; Jong, E.V.d. Chocolate and red wine-a comparison between flavonoids content. Food Chem. 2010, 120, 109-112. [CrossRef]

29. Stockham, K.; Sheard, A.; Paimin, R.; Buddhadasa, S.; Duong, S.; Orbell, J.D.; Murdoch, T. Comparative studies on the antioxidant properties and polyphenolic content of wine from different growing regions and vintages, a pilot study to investigate chemical markers for climate change. Food Chem. 2013, 140, 500-506. [CrossRef] [PubMed]

30. Basli, A.; Soulet, S.; Chaher, N.; Mérillon, J.-M.; Chibane, M.; Monti, J.-P.; Richard, T. Wine polyphenols: Potential agents in neuroprotection. Oxid. Med. Cell. Longev. 2012, 2012, 805762. [CrossRef]

31. Lee, J.; Durst, R.W.; Wrolstad, R.E.; Collaborators. Determination of total monomeric anthocyanin pigment content of fruit juices, beverages, natural colorants, and wines by the ph differential method: Collaborative study. J. AOAC Int. 2005, 88, 1269-1278. [CrossRef] [PubMed]

32. Somers, T.C.; Evans, M.E. Wine quality: Correlations with colour density and anthocyanin equilibria in a group of young red wines. J. Sci. Food Agric. 1974, 25, 1369-1379. [CrossRef] 